\title{
A dynamical analysis of alternative forms of agricultural land tenure
}

\section{Pasquale Commendatore* and Martin Currie ${ }^{* *}$}

This paper explores a dynamic model of an agricultural sector in which in which a class of landowners, who would not contemplate farming themselves, lease land to farmers on fixed rent contracts or on sharecropping contracts and in which farmers are subject to credit rationing by banks. The model, which can exhibit complex dynamics, is used to compare the two pure forms of land tenure and to explore the implications of the coexistence of both types of tenure. The central conclusion from the dynamic simulations is that any simple (static) proposition about the respective merits of the two tenure forms should be treated with extreme caution.

\section{Introduction}

Since Adam Smith there has been an enduring debate on the equivalence of alternative forms of land tenure. ${ }^{1}$ In particular, the Scottish economist attacked the share-rent system. He

\footnotetext{
* University of Naples ‘Federico II’ Dipartimento di Teoria Economica e Applicazioni, Via Mezzocannone 16, 80134, Napoli (Italy). E-mail address: commenda@unina.it

*** School of Economic Studies, University of Manchester, Manchester, M13 9PL, Manchester (UK). E-mail address: martin.currie@man.ac.uk

${ }^{1}$ Surveys of this debate include Quibria \& Rashid (1984), Otsuka \& Hayami (1988), and Otsuka, Chuma \& Hayami (1992).
} 
considered it a hindrance to land improvement, since it forces the tenant to hand over to the landlord, who is not actively contributing in production, a portion of the (value of the) output. In this sense, sharecropping was regarded as equivalent to an excise tax. An exception among classical economists was John Stuart Mill. This author gave a more benign assessment to sharecropping, in part influenced by the reading of the French Physiocrat Sismonde de Sismondi. Moreover, Mill also referred to the flourishing farms of Tuscany that, at his time, were prevalently cultivated by sharecroppers.

The modern approach to sharecropping has originated from some footnotes in Alfred Marshall's Principles of Economics. Marshall restored the tax-equivalence argument providing also a clear-cut diagrammatic exposition extensively employed by subsequent economists. The 'Marshallian' view, which imputes to sharecropping an inefficient resource allocation, was left almost unchallenged until relatively recently when an alternative approach was proposed advocating the efficiency of this type of land tenure. Following the efficiency argument, assuming landlords are able to enforce without costs the labour intensity applied by tenants, this results in no difference between the intensity of labour applied under owneroccupancy or fixed-rent tenancy and the intensity of labour applied under a share contract. ${ }^{2} \mathrm{~A}$ main objection to this approach is that it does not provide a positive reason for the existence of sharecropping.

As often emphasised in the literature, the monitoring ability of the landlord is, in reality, limited. Therefore, he may find it difficult to control how much labour the sharecropper applies in cultivating the land. If the labour inputs applied by tenants or, in an alternative contractual arrangement, by hired workers is not easily observable and in the presence of uncertainty, there is a rationale for sharecropping, as suggested by the agency theory

\footnotetext{
${ }^{2}$ The efficiency argument was originally presented in the controversial contribution of Cheung (1969).
} 
approach. Thus, sharecropping becomes a device that provides incentives and risk-sharing. Indeed, the prevailing view in the current economics literature is that the institution of sharecropping constitutes a response to uncertainty and asymmetric information.

Usually less-developed countries are characterised by imperfect credit markets. It is frequent practice in these countries for landowner and tenant (or labourer) to enter simultaneously into more than one contract linking the land, labour, credit and product markets to overcome insufficient financial resources. ${ }^{3}$ A typical case would involve a financially constrained sharecropper and a landlord who, instead, can freely access the credit market. By altering the terms for a loan, the landlord may be able to induce the sharecropper not only to borrow more but also to increase the labour input intensity. The landlord could also relieve the sharecropper's credit constraint by sharing the cost of (labour or non-labour) inputs and possibly by providing him with the credit to hire the necessary inputs.

In the existing literature, agrarian tenure arrangements are typically investigated by adopting a static approach. Scarce attention has been devoted to how different contractual agreements may affect the dynamics of production and prices. An important feature of agrarian economies, whose significance can easily be underestimated with static analysis, is the structure of the timing of payments. Period by period, this structure influences agricultural output dynamics, especially in the presence of financial constraints on farmers' production plans. There is not a clear presumption that results established in a static framework hold in a dynamical context. The purpose of this study is to use a development of the standard cobweb model to explore and contrast fixed rent tenancy and sharecropping in a dynamical context. In doing so, we examine the implications of credit rationing for behaviour and profitability and,

\footnotetext{
3 Relevant contributions on the relationship between imperfect financial markets and sharecropping are Braverman and Srinivasan (1981), Braverman and Stiglitz (1982), Jaynes (1982), Braverman and Guasch (1984), Shetty (1988), Laffont and Matoussi (1995) and Basu et al. (2000).
} 
in particular, explore the behavioural and institutional factors that govern the likelihood of financial crises.

\section{Model}

In section 2.1, we describe the main features of the agricultural sector and of the production cycle. In Sections 2.2 and 2.3, respectively, we consider in more detail the decisions of fixed rent tenants and of sharecroppers. In Section 2.4, we characterise a stationary equilibrium for the agricultural sector. In Section 2.5, we identify the circumstances under which a particular type of farmer is deemed to be bankrupt.

\subsection{Agricultural sector and the production cycle}

The agricultural sector is composed of $N$ indivisible farms producing a sole agricultural product, corn. Farms are owned by a separate class of landlords who would not contemplate farming the land themselves. A farm may be operated by a fixed rent tenant or by a sharecropper, the proportion of farms operated by fixed rent tenants being $0 \leq \sigma \leq 1$, which is assumed here to be invariant over time. The duration of a tenancy contract corresponds to the duration of the well-defined production period. In the case of fixed rent tenancies, tenants pay an agreed money rent. The market rent is determined competitively at the beginning of each production period and each tenant pays this rent in advance. In contrast, under sharecropping, the sharecropper pays the landlord a stipulated share of the value of the output of the farm. The rental share is an institutional datum, that is, it is determined by 'custom and practice', and share rents are necessarily paid on the completion of production.

Since all decisions and transactions occur at the transitions between production periods, we refer to the transition between period $t-1$ and period $t$ as 'date $t$ '. A description of the time

structure is given in Figure 1 . The $t^{\text {th }}$ production cycle embraces the 'afternoon' of date $t$, the $t^{\text {th }}$ production period itself and the 'morning' of date $t+1$. During the afternoon of date $t$, 
farmers take their decisions and, where appropriate, enter into contracts relating to inputs. Farmers sell the outputs of the $t^{\text {th }}$ production period during the morning of date $t+1$ and use the proceeds to settle any commitments relating to the $t^{\text {th }}$ period. By 'noon' of date $t+1$, the $t^{\text {th }}$ production cycle is completed and the $(t+1)^{\text {th }}$ cycle is ready to start.

The model assumes a representative fixed rent tenant, denoted by subscript $F$, and a representative sharecropper, denoted by subscript $S$. All farmers face the same market prices and, farms being homogeneous in all relevant respects, they face the same technology. Labour being the only non-land input, the production function is:

$$
q_{i, t+1}=A l_{i, t}^{\alpha}
$$

where subscript $i$ denotes the type of farmer (that is, $i=F$ or $S$ ); $l_{i, t}$ represents the total labour input of a farmer of type $i$ during the $t^{\text {th }}$ production period; $q_{i, t+1}$ is the output available for consumption and sale at date $t+1 ; A>0$ is a technological parameter; and $0<\alpha<1$ implies diminishing returns to labour throughout.

The total labour input for a farmer of type $i$ for the $t^{\text {th }}$ period is:

$$
l_{i, t}=h_{i, t}+f
$$

where $h_{i, t}$ denotes hired labour for period $t$; and $f$ denotes the own (family) labour input, this being set by custom, the same for both types and invariant over time. The institutional arrangements are such that the wage of a hired worker comprises both a money payment in advance and a real payment in corn at the time of harvest. Both the money wage rate, denoted by $w$, and the corn wage rate, denoted by $\omega$, are given and invariant over time. Moreover, each farmer retains part of the corn output for own (family) consumption and devotes part of sales receipts to own consumption expenditure (other than on corn). Own corn consumption is given by $\omega f$ and consumption expenditure by $w f$, that is, they correspond, respectively, to the 
corn wage and the money wage which the own labour would have commanded in hired employment.

To finance the hiring of workers, their own consumption expenditure and - in the case of fixed rent tenants - the payment in advance of rents, farmers may supplement their internal financial funds by borrowing from banks subject to institutional limits on borrowing. Banks lend funds only to farmers that are willing and able to risk in production their own financial capital. Banks lack the necessary information to evaluate farms' future profitability; this is due partly to an asymmetry of information between banks and farmers and partly to the uncertainty that is inherent in the agricultural sector. Following Day et al. (1974) in specifying credit rationing, the credit made available by banks is a fixed proportion, $\theta$, of farmers' own financial capital. The rate of interest paid on loans is the same as that received on bank deposits. The interest rate corresponding to the duration of the production period, denoted by $\rho$, is given to the agricultural sector and invariant over time.

We assume that each farmer holds naïve expectations. However, whereas farmers are motivated by the prospect of accumulating wealth, they do not necessarily move immediately to production plans that would maximise expected wealth or, equivalently, that would maximise expected profit for the period. ${ }^{4}$ Rather the representative farmer moves, more or less cautiously, in the direction of the expected wealth maximising plan. We interpret the 'speed' with which the farmer does so as a measure of the degree of the farmer's cautiousness.

The $t^{\text {th }}$ production cycle is concluded during the morning of date $t+1$. From the product, $q_{i, t+1}$, the $i^{\text {th }}$ type of farmer retains $\omega f$ for own consumption; pays $\omega h_{i, t}$ in kind to the workers hired during period $t$; and supplies to the market the remainder, $x_{i, t+1}$ :

\footnotetext{
${ }^{4}$ See Commendatore and Currie (1998) and Onozaki et al. (2000).
} 


$$
x_{i, t+1}=q_{i, t+1}-\omega f-\omega h_{i, t}=q_{i, t+1}-\omega l_{i, t}
$$

The market for corn is competitive, $N$ being sufficiently large that the output of any individual farmer has an imperceptible effect on the market-clearing price. Assuming, for simplicity, that the market demand is unit elastic, the market-clearing price is given by:

$$
p_{t+1}=\frac{E}{N_{F} x_{F, t+1}+N_{S} x_{S, t+1}}
$$

where $E>0, N_{F}=\sigma N$ is the number of farms operated by fixed rent tenants and $N_{S}=(1-\sigma) N$ is the number operated by sharecroppers. The total revenue from sales for the representative farmer of the $i^{\text {th }}$ type is $p_{t+1} x_{i, t+1}$.

\subsection{Fixed rent tenants}

Consider, for the representative fixed rent tenant, the $t^{\text {th }}$ production cycle starting at noon of date $t$. We assume a definite (and natural) sequence of decisions and transactions in the afternoon of date $t$. First, out of financial wealth $W_{F, t}$, each tenant sets aside $w f$ for own consumption. ${ }^{5}$ Second, the market rent for the (forthcoming) $t^{\text {th }}$ production cycle is determined competitively and is duly paid by each fixed rent tenant. Finally, fixed rent tenants hire workers. This sequence has two implications. First, since tenants advance rents, the market rent is itself limited by the available finance. Second, the rent payment has an effect on the representative tenant's wages fund and may thereby impact on the level of labour use.

\footnotetext{
${ }^{5}$ We assume that, if $W_{F, t}-w f<0$, the farmer would be allowed a temporary overdraft to finance own consumption expenditure, $w f$.
} 
The representative fixed rent tenant's maximum financial fund at the start of the cycle for paying both rent and hired workers is a function of his wealth and of the bank policy on credit rationing, as represented by the credit parameter, $\theta$. Specifically, it corresponds to

$$
K_{F, t}^{\phi}=\left\{\begin{array}{cc}
\left(W_{F, t}-w f\right)(1+\theta) & \text { for } W_{F, t}-w f>0 \\
0 & \text { otherwise }
\end{array}\right.
$$

$K_{F, t}^{\phi}$ constitutes an upper-limit on rent. Leaving aside for the moment this financial constraint and the non-negativity constraint on market rent, we assume that competition for tenancies by prospective tenants would result in the market rent moving towards that rent which would have resulted in a zero pure profit in the previous period. The realised pure profit for the $(t-1)^{\text {th }}$ production cycle, as evaluated at date $t$, is given by:

$$
\Pi_{F, t}=p_{t} q_{F, t}-\left[p_{t} \omega+(1+\rho) w\right] l_{F, t-1}-(1+\rho) R_{F, t-1}
$$

where $R_{F, t-1}$ is the rent for that production cycle paid at date $t-1$ and $p_{t} \omega+(1+\rho) w$ is the full cost per unit of labour given the realised price of corn. The assumed rent adjustment hypothesis is:

$$
R_{F, t}=R_{F, t-1}+\lambda \frac{\Pi_{F, t}}{1+\rho}
$$

where $0<\lambda \leq 1$. Taking into account the financial and non-negativity constraints, the market rent adjustment hypothesis becomes:

$$
R_{F, t}=\left\{\begin{array}{ccc}
K_{F, t}^{\phi} & \text { if } & R_{F, t-1}+\lambda \frac{\Pi_{F, t}}{1+\rho}>K_{F, t}^{\phi} \\
R_{F, t-1}+\lambda \frac{\Pi_{F, t}}{1+\rho} \quad \text { if } & K_{F, t}^{\phi} \geq R_{F, t-1}+\lambda \frac{\Pi_{F, t}}{1+\rho} \geq 0 \\
0 & \text { otherwise }
\end{array}\right.
$$


Note that this hypothesis assumes that landowners, who would not contemplate farming themselves, would be prepared to lease their farms even at a zero rent. We refer to $\lambda$ as the 'rent adjustment speed'. It reflects the degree of inertia in the market, with $\lambda=1$ constituting the extreme case of immediate adjustment, subject to the constraints.

The decision as to how much to produce involves knowledge of that labour input that would maximise expected profit for the $t^{\text {th }}$ cycle or, equivalently, would maximise expected wealth at the end of the $t^{\text {th }}$ cycle. For a fixed rent tenant, the necessary condition is that the expected value of the marginal product equal the expected full cost of labour:

$$
p_{t}^{e} \alpha A l_{F, t}^{\alpha-1}=p_{t}^{e} \omega+(1+\rho) w
$$

where $p_{t}^{e}$ is the representative farmer's price expectation at noon of date $t$. Given naïve expectations, $p_{t}^{e}=p_{t}$, that is, the farmer bases his decision in the afternoon of date $t$ on a price expectation equal to the actual price realised in the morning. Solving gives:

$$
l_{F, t}^{*}=\left[\frac{p_{t}^{e} \alpha A}{p_{t}^{e} \omega+(1+\rho) w}\right]^{\frac{1}{1-\alpha}}
$$

Being a sunk cost, the fixed rent does not have an effect on $l_{F, t}^{*}$. However, the rent does affect the representative tenant's ability to hire additional labour. Specifically, the fixed rent tenant's wages fund is given by:

$$
K_{F, t}=K_{F, t}^{\phi}-R_{F, t} \geq 0
$$

With $K_{F, t} / w$ being the maximum amount of labour that the farmer could hire given the wages fund, actual labour use is governed by: 


$$
l_{F, t}=\left\{\begin{array}{ccc}
f+\frac{K_{F, t}}{w} & \text { if } & l_{F, t-1}+\tau\left(l_{F, t}^{*}-l_{F, t-1}\right)>f+\frac{K_{F, t}}{w} \\
l_{F, t-1}+\tau\left(l_{F, t}^{*}-l_{F, t-1}\right) & \text { if } & f+\frac{K_{F, t}}{w} \geq l_{F, t-1}+\tau\left(l_{F, t}^{*}-l_{F, t-1}\right) \geq f \\
f & \text { if } & l_{F, t-1}+\tau\left(l_{F, t}^{*}-l_{F, t-1}\right)<f
\end{array}\right.
$$

where $0<\tau \leq 1$ is the 'production adjustment speed'. For $\tau=1$, the representative farmer would move immediately to the production plan that maximises expected profit, subject to the financial constraint and the non-negativity of hired labour. For $\tau<1$, the farmer moves more or less cautiously in the direction of that plan; the lower $\tau$, the more cautious the farmer. Bearing in mind that the representative tenant farmer advances both rents and wages, his net borrowing for the $t^{\text {th }}$ production cycle is given by:

$$
B_{F, t}=w h_{F, t}+R_{F, t}-\left(W_{F, t}-w f\right)=w l_{F, t}+R_{F, t}-W_{F, t}
$$

In the case in which wealth net of the tenant's own consumption expenditure exceeds wage and rent payments, i.e. $B_{F, t}<0$, what is left is banked and constitutes a deposit on which the same rate of interest, $\rho$, as for borrowing is applied.

The fixed rent tenant's wealth at the end of the $t^{\text {th }}$ production cycle is:

$$
\begin{aligned}
W_{F, t+1} & =p_{t+1} x_{F, t+1}-(1+\rho) B_{F, t} \\
& =(1+\rho) W_{F, t}+p_{t+1} q_{F, t+1}-\left[p_{t+1} \omega+(1+\rho) w\right] l_{F, t}-(1+\rho) R_{F, t} \\
& =(1+\rho) W_{F, t}+\Pi_{F, t+1}
\end{aligned}
$$

$W_{F, t+1}$ determines the tenant's own fund available for financing the subsequent $(t+1)^{\text {th }}$ production cycle.

\subsection{Sharecroppers}

We assume that a sharecropping contract stipulates only the rental share, leaving the sharecropper free to determine the level of hired labour. Denoting the (institutionally given) 
rental share by $r_{S}$, where $0<r_{S}<1$, the money value of the rental payment for a representative sharecropped farm is $r_{S} p_{t+1} q_{S, t+1}$; it thus depends on what the price of corn turns out to be. The expected pure profit of the sharecropper for the $t^{\text {th }}$ production cycle is:

$$
\Pi_{S, t+1}^{e}=\left(1-r_{S}\right) p_{t}^{e} q_{S, t+1}-\left[p_{t}^{e} \omega+(1+\rho) w\right] l_{S, t}
$$

To maximise expected pure profit would require that the sharecropper equate his own share of the expected value of the marginal product of labour to the expected full cost of labour, that is:

$$
\left(1-r_{S}\right) p_{t}^{e} \alpha A l_{S, t}^{\alpha-1}=p_{t}^{e} \omega+(1+\rho) w
$$

Solving yields:

$$
l_{S, t}^{*}=\left[\frac{\left(1-r_{S}\right) \alpha A p_{t}^{e}}{p_{t}^{e} \omega+(1+\rho) w}\right]^{\frac{1}{1-\alpha}}
$$

For a given expected price, comparing expression (17) with the equivalent expression (10) for fixed rent tenancy establishes that $l_{S, t}^{*}$ under sharecropping is less than $l_{F, t}^{*}$ under fixed rent tenancy. Whereas under a fixed rent contract the tenant retains the whole of the marginal product of labour, the sharecropper retains only a fraction of the marginal product, reducing the latter's incentive to use labour.

In the context of our model, there is a further difference between fixed rent tenancy and sharecropping. For the former, the rental payment impacts on the wages fund. In contrast, since sharecropping rents are paid ex post, the representative sharecropper's wages fund in the afternoon of date $t$ is simply:

$$
K_{S, t}=\left\{\begin{array}{ccc}
\left(W_{S, t}-w f\right)(1+\theta) & \text { for } & W_{S, t}-w f>0 \\
0 & \text { otherwise }
\end{array}\right.
$$


The actual labour input is governed by the same rule as (12) (with appropriate change in subscripts), the production adjustment speed for sharecroppers being the same as for fixed rent tenants. The representative sharecropper's hired labour is $h_{S, t}=l_{S, t}-f$; and net borrowing is $B_{S, t}=w l_{S, t}-W_{S, t}$. After the sale of the produce during the morning of date $t+1$, the sharecropper pays the landlord the total rent $r_{S} p_{t+1} q_{S, t+1}$. The representative sharecropper's wealth at the end of the $t^{\text {th }}$ production cycle is

$$
\begin{aligned}
W_{S, t+1} & =p_{t+1} x_{S, t+1}-r_{S} p_{t+1} q_{S, t+1}-(1+\rho) B_{S, t} \\
& =(1+\rho) W_{S, t}+\left(1-r_{S}\right) p_{t+1} q_{S, t+1}-\left[p_{t+1} \omega+(1+\rho) w\right] l_{S, t} \\
& =(1+\rho) W_{S, t}+\Pi_{S, t+1}
\end{aligned}
$$

where $\Pi_{S, t+1}$ is the realised pure profit for the $t^{\text {th }}$ period.

\subsection{Stationarity}

We must now characterise for the agricultural sector an equilibrium in which all variables are stationary except for wealth levels and financial funds. There are three key features of a thorough-going stationary equilibrium. First, the stationary labour input of each type of farmer must maximise expected profit on the basis of a price expectation which is being realised. Second, in a stationary equilibrium, for neither type of farmer is the financial constraint binding. Finally, the stationary fixed rent must be such that each fixed rent tenant earns zero pure profit.

In Figure 2, which depicts a stationary equilibrium for the agricultural sector, ${ }^{6}$ the representative fixed rent tenant uses labour input:

\footnotetext{
${ }^{6}$ Figure 2 depicts the case where stationarity involves both types hiring strictly positive quantities of labour. Depending on the parameters, stationarity could involve a situation where both types use only own labour or a
} 


$$
\bar{l}_{F}=\left[\frac{\bar{p} \alpha A}{\bar{p} \omega+(1+\rho) w}\right]^{\frac{1}{1-\alpha}}
$$

where the value of the marginal product of labour equals the full cost of labour. He pays a fixed rent of $\bar{R}_{F}=\operatorname{area}\{A+B+C\}$; and receives a zero pure profit. The representative sharecropper uses labour input:

$$
\bar{l}_{S}=\left(1-r_{S}\right)^{\frac{1}{1-\alpha}} \bar{l}_{F}
$$

where his own share of the value of the marginal product of labour equals the full cost of labour. He pays a rent of $r_{S} \bar{p} \bar{q}_{S}=\operatorname{area}\{A\}$; and receives a positive pure profit of $\bar{\Pi}_{S}=$ area $\{B\}$. Figure 2 confirms the celebrated Marshallian proposition. If the share rent arrangement does not stipulate the labour input and there are not binding constraints, the actual labour use under sharecropping is less than under fixed rent tenancy. The stationary market clearing price satisfies:

$$
\bar{p}=\frac{E}{N\left(\sigma \bar{x}_{F}+(1-\sigma) \bar{x}_{S}\right)}
$$

where $\bar{x}_{i}=\bar{q}_{i}-\omega \bar{l}_{i}$ and $\bar{q}_{i}=A \bar{l}_{i}^{\alpha}$. Note, from (22), that the stationary equilibrium depends on the proportion of fixed rent tenants, $\sigma$. It is easily demonstrated that $\bar{p}$ is decreasing in $\sigma$.

\subsection{Financial crises}

The possibility of farmers borrowing raises the possibility of bankruptcy. We will say that a sufficient condition for a 'financial crisis' to have occurred is that either (representative) type

situation where sharecroppers use only own labour with fixed rent tenants hiring additional labour (but not a situation where fixed rent tenants use only own labour with sharecroppers hiring additional labour). 
of farmer is sufficiently in debt that they would not be able to get out of debt even under the most optimistic scenario for them.

Consider first the sufficient condition for the bankruptcy of fixed rent tenants. Suppose that at noon of date $t$ the wealth of a representative fixed rent tenant is $W_{F, t}<0$, so that $K_{F, t}^{\phi}=0$. This implies that the market rent for period $t$ would be zero and that each tenant would use solely own labour to supply $\tilde{x}$ to the market, where

$$
\tilde{x}=A f^{\alpha}-\omega f=\tilde{q}-\omega f
$$

The market-clearing price will depend not only on the output of the fixed rent tenants but also on the output of the sharecroppers. From the perspective of the fixed rent tenants, the most optimistic scenario is that sharecroppers also use only own labour, since this would maximise the product price received by fixed rent tenants. In this event, each farmer (of whatever type) would produce $\tilde{x}$ and the corresponding price would be:

$$
\tilde{p}=\frac{E}{N \tilde{x}}
$$

The pure profit of a fixed rent tenant would then be:

$$
\Pi_{F, t+1}=\tilde{p} \tilde{q}-[\tilde{p} \omega+(1+\rho) w] f \equiv \tilde{\Pi}_{F}
$$

Using (14) and (25):

$$
\operatorname{for} W_{F, t}<0 \quad \rho\left|W_{F, t}\right|>\tilde{\Pi}_{F} \Rightarrow W_{F, t+1}<W_{F, t}
$$

That is, if at date $t W_{F, t}<0$ and $\rho\left|W_{F, t}\right|>\tilde{\Pi}_{F}$, the representative fixed rent tenant farmer would fall further into debt over the ensuing period, i.e., his wealth would become more negative, even under the most optimistic scenario and he is deemed to be bankrupt. In other words, a financial crisis is deemed to have occurred, if the representative fixed rent tenant farmer's debt would not be cleared by his (hypothetically) receiving the discounted present 
value of the future stream of profits assuming that all farmers, including sharecroppers, use solely own labour.

The sufficient condition for the bankruptcy of sharecroppers is analogous to that of fixed rent tenants. If $W_{S, t}<0$, so that $K_{S, t}=0$, the sharecropper would use solely own labour to supply $\tilde{x}$ to the market. Assuming - the most optimistic scenario - that fixed rent tenants also use only own labour, the market price would be $\tilde{p}$, the sharecropper's rental payment would be $r_{S} \tilde{p} \tilde{q}$, and the sharecropper's realised pure profit for the $t^{\text {th }}$ production cycle would be:

$$
\Pi_{S, t+1}=\left(1-r_{S}\right) \tilde{p} \tilde{q}-[\tilde{p} \omega+(1+\rho) w] f \equiv \tilde{\Pi}_{S}
$$

Using (19) and (27):

$$
\text { for } W_{S, t}<0 \quad \rho\left|W_{S, t}\right|>\tilde{\Pi}_{S} \Rightarrow W_{S, t+1}<W_{S, t}
$$

That is, if at date $t W_{S, t}<0$ and $\rho\left|W_{S, t}\right|>\tilde{\Pi}_{S}$, the representative sharecropper would fall further into debt over the ensuing period even under the most optimistic scenario and is deemed to be bankrupt. Note well that $\tilde{\Pi}_{S}<\tilde{\Pi}_{F}$ : this is because even if the financial position of the sharecropper is 'critical', he is still obliged to hand to the landlord a fraction of the value of the output. ${ }^{7}$ Consequently, comparing condition (28) with condition (26), suggests a presumption that sharecroppers may be more prone to bankruptcy than fixed rent tenants. However, we need to conduct simulations to investigate this further.

\footnotetext{
${ }^{7}$ We assume that $\tilde{\Pi}_{F}>\tilde{\Pi}_{S} \geq 0$. Otherwise an agricultural sector with sharecroppers would not be viable.
} 


\section{Dynamics}

We explore the dynamics of the model using simulations. Section 3.1 examines and compares pure fixed rent tenancy $(\sigma=1)$ and pure sharecropping $(\sigma=0)$. Section 3.2 examines some of the implications of the general model where both types coexist. For all the simulations we use the following constellation of parameters: $N=1000, \alpha=0.8, A=10, w=1, \omega=0.4, \rho=0.1$, $f=1$ and $E=10000$.

\subsection{Comparison of pure tenure forms}

With universal fixed rent tenancy, where $\sigma=1$, the parameters imply stationary state solutions $\bar{h}_{F} \cong 6.158, \bar{l}_{F} \cong 7.158, \bar{q}_{F} \cong 48.288, \bar{x}_{F} \cong 45.425, \bar{p} \cong 0.22$ and $\bar{R}_{F} \cong 1.933{ }^{8}$ To investigate the long term behaviour of the dynamical system, we use bifurcation diagrams that show the behaviour of some endogenous variable of interest as a multi-valued function of some particular parameter. Figure 3 depicts, for pure fixed rent tenancy, bifurcation diagrams for price with respect to the production adjustment speed $\tau$ for (a) $\theta=0$ and (b) $\theta=2$. There is a critical value of the production adjustment speed, $\tau_{F}^{c} \cong 0.583$, below which tenant farmers' own funds are always sufficient to finance their desired labour hiring. That is, in Figure 3, the long-term behaviour of price is the same whatever the value of $\theta$ for adjustment speeds below $\tau_{F}^{c}$. For 'slow' production adjustment speeds, the fixed point is stable. However, as the speed increases through $\tau_{F}^{b i f} \cong 0.425$, the fixed point loses its stability, giving rise to a

\footnotetext{
8 We postulate the following initial conditions: $l_{F, 0}=0.99 \bar{h}_{F, 0}+f \cong 7.097$, implying $p_{1}=p_{1}^{e} \cong 0.222$; $R_{F, 0}=0 ;$ and $W_{F, 1}=w l_{F, 0} \cong 7.097$.
} 
period-doubling route to chaotic behaviour. ${ }^{9}$ For speeds below $\tau_{F}^{c}$, wealth increases broadly in line with the rate of interest, that is, the major component of increases in wealth is the interest on the tenant's (growing) bank deposits. For adjustment speeds above $\tau_{F}^{c}$, the tenant farmer does wish to borrow; and behaviour depends on the magnitude of $\theta$. Where $\theta=0$, that is, where farmers must rely entirely on own funds for hiring additional labour, the dynamics exhibits a period-two cycle for speeds above the critical value $\tau_{F}^{c}$. Period-two cycles emerge because the financial constraint is binding. Specifically, in alternating periods, the farmer has insufficient own funds to hire the desired additional labour. Hired labour, total output, market supply and price all follow period-two cycles. Moreover, the wealth of the representative tenant follows a period-two cycle. Consider now the case where $\theta=2$. For production adjustment speeds below the critical value $\tau_{F}^{c}$, the behaviour of the sector is the same as for $\theta=0$. The explanation is simply that, since tenant farmers' own funds are sufficient to finance desired labour hiring, the ability to borrow makes no difference. Above the critical production adjustment speed, farmers take advantage of their ability to borrow. Doing so typically results in considerably greater variations in labour use, output and price, with price hitting its maximum level, $\tilde{p}$, the latter being the market-clearing price when all farmers use only

\footnotetext{
${ }^{9}$ This is consistent with Onozaki et al. (2000), who demonstrate rigorously that adaptive production adjustment in a (simpler) cobweb model with normal demand and supply functions and naïve expectations can give rise to chaotic behaviour.
} 
family labour. ${ }^{10}$ We may note finally that financial crises do not occur for $\theta=2$; however, they may occur for $\theta>2$.

Figure 4 shows the significance of the rent adjustment speed, $\lambda$, for distribution. Specifically, it shows the average share of rent in the value of output from $t=51$ to $t=1050$ as a function of $\tau$ for $\theta=2$ and for $\lambda=0.1, \lambda=0.5$, and $\lambda=1$. Given the Cobb-Douglas production function, this share equals $(1-\alpha) /(1+\rho)$ for production adjustment speeds sufficiently slow that the fixed point is an attractor. As $\tau$ increases, the average share of rent initially falls but then recovers — the point and the extent of the recovery depending on $\lambda$. For each curve, the sharp increase in the average share of rent occurs at the corresponding critical speed. Figure 4 confirms that the average share of rent is higher, the lower the degree of inertia in the market, i.e., the more rapid the rent adjustment.

For the case of pure sharecropping, where $\sigma=0$, we set the rental share at $r_{S}=0.5$, the latter being commonly observed in sharecropping contracts. ${ }^{11}$ The chosen constellation of parameters involves a fixed point for which $\bar{h}_{S} \cong 2.344, \bar{l}_{s} \cong 3.344, \quad \bar{q}_{s} \cong 26.265$, $\bar{x}_{S} \cong 24.928, \bar{p} \cong 0.401$ and $\bar{\Pi}_{S} \cong 1.054 .^{12}$ Figure 5 depicts bifurcation diagrams for price with respect to the production adjustment speed for (a) $\theta=0$ and (b) $\theta=2$. The fixed point

\footnotetext{
${ }^{10}$ For example, the ability to borrow may lead to a sufficiently high hiring of labour in period $t$ (and a sufficiently low price at date $t+1$ ) that wealth at date $t+1$ is negative; this, in turn, forces each farmer to rely solely on own labour in period $t+1$, resulting in the maximum price, $\tilde{p}$; the receipt of $\tilde{\pi}$ per period, sooner or later, enables each farmer again to employ labour; and so on.

${ }^{11}$ The terms for sharecropping is métayage in France and mezzadria in Italy; both terms mean one-half.

${ }^{12}$ The initial conditions are $l_{0}=0.99 \bar{h}_{S}+f \cong 3.32, p_{1}=p_{1}^{e} \cong 0.403$ and $W_{S, 1}=w l_{S, 0} \cong 3.32$.
} 
loses its stability as $\tau$ increases through $\tau_{S}^{b i f} \cong 0.451 .{ }^{13}$ The critical speed above which sharecroppers wish to borrow is $\tau_{S}^{c} \cong 0.712$.

Digressing briefly, it is instructive at this point to compare briefly the benchmark case $r_{S}=0.5$ with the case $r_{S}=1-\alpha=0.2$. The significance of $r_{S}=1-\alpha$ is that this would maximise the expected rent of the individual landlord, assuming that the output from his own farm has an imperceptible effect on the market-clearing price. ${ }^{14}$ Figure 6 compares for $0.4 \leq \tau \leq 1$ average pure profit and average rent for the cases $r_{S}=0.5$ and $r_{S}=1-\alpha=0.2$. As shown in the lower part of Figure 6 , for most speeds above $\tau \cong 0.593$, the representative sharecropper's average profit is higher for $r_{S}=0.5$ than for $r_{S}=0.2$. Moreover, as the upper part of Figure 6 shows, landlords are systematically better off in the long-run with a rental share $r_{S}=0.5$ than with a rental share $r_{S}=0.2$. The explanation for this is that there is a conflict between the interests of an individual landlord and those of landlords as a group. Whereas an individual landlord would benefit if only he negotiated a rental share of $1-\alpha$, if all landlords were to do so the resulting increase in industry output and fall in average price would be harmful to landowners as a group.

Returning to Figure 5, a comparison with Figure 3 indicates three main differences between pure sharecropping and pure fixed rent tenancy. First, the speed at which the fixed point becomes unstable is higher for sharecropping than for fixed rent tenancy, i.e.,

\footnotetext{
${ }^{13}$ In Figure 5, compared to Figure 3, there is a much wider range of period doubling before the financial constraint has an impact.

${ }^{14}$ Maximising the expected rent for period $t$ involves finding the $r_{S}$ that solves $\underset{r_{S}}{\operatorname{Max}} r_{S} p_{t}^{e} q_{t+1}=r_{S} p_{t}^{e} A l_{S, t}^{\alpha}$, subject to the constraint that the sharecropper responds with the profit maximising level of labour. The first order condition is $r_{S} p_{t}^{e} A l_{S, t}^{\alpha}\left[1-(\alpha /(1-\alpha))\left(r_{S} /\left(1-r_{S}\right)\right)\right]=0$, which is solved when $r_{S}=1-\alpha$. Note that the optimal rental share for the landlord is independent of the expected price.
} 
$\pi_{S}^{b i f} \cong 0.451$ versus $\pi_{F}^{b i f} \cong 0.425$. Second, as one would expect, when farmers have sufficient wealth to finance the desired labour hiring, that is, when the dynamics are unconstrained, price is more variable but higher on average under sharecropping compared to fixed rent tenancy. Third, the critical production adjustment speed under sharecropping is significantly higher than under fixed rent tenancy, i.e., $\tau_{S}^{c} \cong 0.712$ versus $\tau_{F}^{c} \cong 0.583$; this is because the fixed rent tenants pay rents in advance.

Figures 7 and 8 also compare universal fixed rent tenancy and sharecropping. Figure 7 plots for $\theta=0, \lambda=1$ and $r_{S}=0.5$, average pure profit and the variance of profit for pure fixed rent tenancy (thin line) and for pure sharecropping (thick line). For both types of land tenure, average profit decreases as $\tau$ is increased. The similarities, however, end here. Indeed, for a representative sharecropper, average pure profit is normally higher, and the variance of profit is lower compared to fixed rent tenancy. Moreover, as shown in Figure 8, for the representative landlord sharecropping guarantees higher and less volatile average rental payments. $^{15}$

\subsection{Coexistence of fixed rent tenants and sharecroppers}

Consider now the coexistence of fixed rent tenants and sharecroppers and, in particular, the significance of $\sigma$ for differences in profitability and for the likelihood of financial crises. Consider first the differences between sharecroppers and fixed rent tenants in the case in which they are equal in number $(\sigma=0.5)$ and in which they have to rely on own funds $(\theta=0)$.

\footnotetext{
${ }^{15}$ Notice that setting $\theta=2$ does not modify the conclusion that universal sharecropping involves higher average profitability and lower volatility of profit and rent compared to fixed rent tenancy.
} 
At $\sigma=0.5$, the parameter values imply $\bar{h}_{S}=0 ; \bar{h}_{F} \cong 11.581 ; \bar{q}_{S}=\tilde{q} \cong 4.988 ; \bar{q}_{F} \cong 75.816$; $\bar{x}_{S}=\tilde{x}=4.588 ; \bar{x}_{F} \cong 70.784 ; \bar{p} \cong 0.249 ;$ and $\bar{\Pi}_{S} \cong 0.045 ;$ and $\bar{R}_{F} \cong 3.442 .{ }^{16}$

Note that any difference in the behaviour of the two types of tenants must derive (i) from the fact that, in general, sharecroppers' use less labour than fixed rent tenants, that is, excluding the case in which both are financially constrained, and (ii) from the fact that, by their nature, share rents are paid after production, whereas fixed rents are assumed here to be advanced. Therefore, the payment of fixed rents impacts on the ability of farmers to hire the desired additional labour, whereas the rental share affects 'directly' the desired level of additional labour. The lower part of Figure 9, which is based on $\lambda=0.25$ and $0.4 \leq \tau \leq 1$, shows the average difference between labour use by fixed rent tenants and that by sharecroppers, i.e., the mean of $\left(l_{F, t}-l_{S, t}\right)$ from $t=51$ to $t=1050$. For production speeds below the bifurcation value $\tau^{\text {bif }} \cong 0.465$, the difference in average labour use corresponds to the stationary equilibrium $\bar{l}_{F}-\bar{l}_{S} \cong 11.581$. For $\tau^{b i f} \leq \tau<\tau_{F}^{c}$ this difference grows, as fixed rent tenants find it increasingly convenient to increase the labour input (sharecroppers being most of the time constrained), where $\tau_{c}^{F} \cong 0.71$ represents the critical value of the production speed which applies to fixed rent tenants. For $\tau \geq \tau_{F}^{c}$, the difference in labour use decreases progressively until eventually it falls below the stationary equilibrium value, as for both fixed rent tenants and sharecroppers the wages fund is binding and, in some periods, only family labour is used in production, especially above $\tau_{S}^{c}>\tau_{F}^{c}$, where $\tau_{S}^{c} \cong 0.755$ represents the critical value of the production speed which applies to sharecroppers. The middle and upper parts of Figure 9 show respectively the difference in the average pure profit and the difference

\footnotetext{
16 The initial conditions are: $l_{F, 0}=f+0.99 \bar{h}_{F} \cong 12.465 ; W_{F, 1}=w l_{F, 0} \cong 12.465 ; l_{S, 0}=f=1 ; W_{S, 1}=w l_{S, 0}=1$; and $p_{1} \cong 0.25$.
} 
in the average rent between fixed rent tenancy and sharecropping, that is, $\left(\Pi_{F, t+1}-\Pi_{S, t+1}\right)$ and $\left(R_{F, t}-\frac{r_{S} p_{t+1} q_{S, t+1}}{1+\rho}\right)$.

The most interesting feature of Figure 9 is that, for most speeds above $\hat{\tau} \cong 0.594$, the average rental payment in sharecropping is higher than in fixed rent tenancy. The difference between average rents under the two institutional arrangements depends on the parameters of the model and, in particular, on the degree of inertia in the fixed rent market. Thus, as $\lambda$ is increased the value of $\tau$ for which both pure profit and rent are higher in sharecropping than in fixed rent tenancy increases. For example, $\hat{\tau} \cong 0.592$ for $\lambda=0.01, \hat{\tau} \cong 0.933$ for $\lambda=0.5$ and no value of $\hat{\tau}$ can be found for $\lambda \geq 0.8$. This value $\hat{\tau}$ also changes as the proportion of fixed rent tenants changes: assuming $\lambda=0.25, \hat{\tau} \cong 0.964$ for $\sigma=0.001, \hat{\tau} \cong 0.851$ for $\sigma=0.25$, $\hat{\tau} \cong 0.556$ for $\sigma=0.75$ and $\hat{\tau} \cong 0.523$ for $\sigma=0.999$.

We turn now to the likelihood of financial crises comparing the relative robustness of fixed rent tenancy and sharecropping in the model with heterogeneous farmers. In Figure 10 we allow $\sigma$ and $\tau$ to vary simultaneously, $\sigma$ from 0 to 1 and $\tau$ from 0.7 to 1 , and we conduct the experiment for $\theta=1, \theta=1.5$ and $\theta=2$. We use tiles of different colour to record if by date $T=50$ a crisis has occurred or not and, if it has, which group of farmers was the first to go bankrupt. A white tile is used to register sharecroppers incurring a crisis first; a black tile is used to register fixed rent tenants incurring a crisis first; and a grey tile signifies that by date $T$ for neither type of tenant has a crisis occurred. ${ }^{17}$

\footnotetext{
${ }^{17}$ Notice that the stationary state depends on the relative proportions of fixed rent tenants and sharecroppers: increasing $\sigma$ from $\sigma=0$ to $\sigma=1$ reduces the stationary equilibrium price from $\bar{p} \cong 0.401$ to $\bar{p} \cong 0.22$, with the stationary values of the other variables changing accordingly.
} 
What can be inferred from Figure 10? First, although for the selected credit parameters, financial crises do not occur for the pure forms of land tenure, they do occur with heterogeneous tenure systems. Second, crises are, in general, more likely when the number of fixed rent tenants is relatively small or when the number of sharecroppers is relatively small, than for intermediate values of $\sigma$. Specifically, crises are more likely to occur for $0<\sigma$ $\leq 0.25$ and for $0.75 \leq \sigma \leq 1$ than for $0.25<\sigma<0.75$. Third, when crises occur, it is the type of farmer in the smaller proportion that more often goes bankrupt. For example, a $\sigma$ close to zero implies that the number of fixed rent tenants is also close to zero, so that the behaviour of market is dominated by sharecroppers, and fixed rent tenants are particularly vulnerable to financial crisis. Finally, for $\theta=1$, sharecropping appears to be substantially more robust than fixed rent tenancy, whereas for $\theta=1.5$ and $\theta=2$, sharecroppers go bankrupt over a relatively wider range of values of the production adjustment speed compared to fixed rent tenants. That is, for low values of the credit rationing parameter the lower use of labour favours the survival of sharecroppers, whereas the particular structure of rental payments makes progressively more difficult the sharecroppers survival as $\theta$ is increased. The financial fragility of fixed rent tenants, instead, is relatively independent of $\theta$.

\section{Some final comments}

In this paper we have explored a dynamic model of an agricultural sector in which a class of landowners, who would not contemplate farming themselves, lease land to farmers on fixed rent contracts or on sharecropping contracts. Although we invoke various simplifying assumptions - for example, representative farmer types; a Cobb-Douglas production function; and wage rates that are given to the agricultural sector as a whole - the model can exhibit complex dynamics, involving periodic or even chaotic behaviour. In comparing pure fixed rent tenancy and pure sharecropping, the central conclusion from the dynamic simulations is a negative but nevertheless important one, namely, that any simple (static) proposition about the 
respective merits of the two tenure forms should be treated with extreme caution. Certainly we have find parameter values for which both landowners and farmers would, on average, be better-off under sharecropping contracts than under fixed rent contracts, even though the tenant is free to choose the level of hired labour under both types of contract. Of course, one might well expect members of the agricultural sector to be better-off under pure sharecropping than under pure fixed rent tenancy, since labour inputs would normally be lower, and product prices normally higher, under the former. It is very important therefore to note that, where we explored the implications of coexistence of the two forms of tenure, both types of farmer receive the same product price at any date and yet there are parameters for which profits and rents are, on average, higher under sharecropping.

Finally, we should re-iterate the importance of credit and the possibility of financial crises. Propositions based on the assumption of a perfectly competitive financial market are particularly suspect. In reality, producers do have financial constraints on their behaviour and they do encounter financial crises. Key aspects of our analysis are the identification of a formal condition for identifying the circumstances in which farmers of a particular type would be deemed to be bankrupt and the demonstration, using simulations, that financial crises are most likely when there is an imbalance in the proportions of the two types. 


\section{Bibliography}

Basu, K., Bell, C. and Bose, P. (2000), Interlinkage, limited liability and strategic interaction. Journal of Economic Behaviour and Organization, 42, 445-462.

Braverman, A. and Guasch, J.L. (1984), Capital requirements, screening and interlinked sharecropping and credit contracts, Journal of Development Economics, 14, 359-74.

Braverman, A. and Srinivasan, T.N. (1981), Credit and sharecropping in agrarian societies, Journal of Development Economics, 9, 289-312.

Braverman, A. and Stiglitz, J.(1982), Sharecropping and the interlinking of agrarian markets, American Economic Review, 72, 695-715.

Braverman, A. and Stiglitz, J.E. (1986), Cost-Sharing Arrangements, Employment and Wages in Rural Labor Markets in Asia, New Haven and London, Yale University Press,

Cheung, S.N. (1969), The Theory of Share Tenancy, Chicago, University of Chicago Press.

Commendatore, P. and Currie, M. (1998), Market dynamics of the agricultural sector: credit rationing and financial crises. Discussion papers series n. 9814, School of Economic Studies, The University of Manchester, Manchester.

Day, R.H, Morley S. and Smith K.R. (1974), Myopic optimizing and in a micro-model of industrial growth, American Economic Review, 64, 11-23.

Jaynes, G.D.(1982), Production and distribution in agrarian economies, Oxford Economic Papers, 34, 346-367.

Laffont, J.J. and Matoussi, M.S. (1995), Moral hazard, financial constraints and sharecropping in El Oulja, Review of Economic Studies, 62, 381-399.

Onozaki, T., Sieg, G., Yokoo, M. (2000), Complex dynamics in a cobweb with adaptive production adjustment, Journal of Economic Behaviour and Organization, 41, 101-115. 
Otsuka, K., Chuma, H. and Hayami Y. (1992), Land and labor contracts in agrarian economies: theories and facts, Journal of Economic Literature, 30, 1965-2018.

Otsuka, K., Hayami, Y. (1988), Theories of share tenancy: A critical survey, Economic Development and Cultural Change, 31-69.

Quibria, M.G. and Rashid, S. (1984), The puzzle of sharecropping: A survey of theories, World Development, 12, 103-14.

Shetty, S. (1988), Limited liability, wealth differences and tenancy contracts in agrarian economics, Journal of Development Economics, 29, 1-22.

Smith, A. (1776), The Wealth of Nations, London, Strahan and Cadell. 